\title{
Quarantine Hotels: The Adaptation of Hotels for Quarantine Use in Australia
}

\author{
Demet Dincer $^{1, *}$ and Ozgur Gocer ${ }^{2}$ (D) \\ 1 The School of Built Environment, University of New South Wales, Kensington Campus, \\ Sydney, NSW 2052, Australia \\ 2 The Sydney School of Architecture, Design and Planning, The University of Sydney, Sydney, NSW 2006, \\ Australia; ozgur.gocer@sydney.edu.au \\ * Correspondence: d.dincer@unsw.edu.au
}

Citation: Dincer, D.; Gocer, O. Quarantine Hotels: The Adaptation of Hotels for Quarantine Use in Australia. Buildings 2021, 11, 617 . https://doi.org/10.3390/ buildings11120617

Academic Editor: Dirk H.R. Spennemann

Received: 1 November 2021 Accepted: 2 December 2021 Published: 6 December 2021

Publisher's Note: MDPI stays neutral with regard to jurisdictional claims in published maps and institutional affiliations.

Copyright: (C) 2021 by the authors Licensee MDPI, Basel, Switzerland. This article is an open access article distributed under the terms and conditions of the Creative Commons Attribution (CC BY) license (https:/ / creativecommons.org/licenses/by/ $4.0 /)$.

\begin{abstract}
The COVID-19 global health crisis has spatial implications concerning social isolation to control the spread of the virus. The preventive measures require travelers to stay in mandatory quarantine for 14 days upon arrival from another country. Due to a shortage of government facilities, more hotels have started to function as quarantine facilities. This research focuses on quarantine hotels in Australia, as one of the first countries to implement an international border restriction, to evaluate the spatial needs of users and what see outcomes can be identified. By primarily focusing on hotel users' well-being during the isolation period, this paper responds to an information gap regarding the quarantine hotel system by providing user opinions on the negative and positive factors affecting their well-being. A survey with multiple-choice and open-ended questionnaire items was conducted with 54 participants to investigate their experiences in quarantine hotels. Among the nine key sources of well-being, the three highest-scored responses were an operable window (4.7), ventilation (4.5), and natural lighting (4.3). Access to the outdoor environment via a balcony or operable window was an acute and fundamental requirement for guests. Additionally, participants mentioned that they are unwilling to return to the hotel where they spent their quarantine, which raises issues regarding the future of hotels.
\end{abstract}

Keywords: quarantine; hotel room; COVID-19; wellbeing; spatial adaptation; Australia

\section{Introduction}

The COVID-19 pandemic has substantially impacted hotels in two correlated ways. Firstly, the pandemic had a global socio-economic impact on the tourism industry. For example, COVID-19 related restrictions resulted in 7.6 million fewer international arrivals to Australia, 45 million fewer domestic overnight trips, and 84 million fewer day trips in 2020 compared to 2019 [1]. Meanwhile, preventive measures were applied to inbound and outbound travelers to control the spread of COVID-19, and hotels experienced an adaptation period acting as quarantine hotels. The tourism industry began hosting international travelers for the mandatory isolation period [2].

Travelers were requested to self-quarantine for two weeks in most countries, such as Australia, China, and India, by isolating in their homes or in an observation center supervised by the government. Due to the shortage of quarantine-specific government facilities, hotels functioned as quarantine facilities by using guestrooms for transient accommodation. Additional to travelers, hotels provided accommodation for health workers and COVID-19 patients experiencing mild symptoms in some countries, such as China [3]. International travelers flying to Australia were required to quarantine under public health orders. Australia was one of the first countries to implement international border restrictions at the beginning of the pandemic to prevent the virus from spreading. Quarantine hotels played a significant role, effectively acting as a secondary border. The first COVID-19 case in Australia was recorded in January 2020. Two months later, a 14-day quarantine 
requirement was applied to returning travelers, beginning on 28 March 2020, remaining in place as of October 2021 [4]. Guests were not advised which hotel they would be staying in until or close to their arrival. The government charged each traveler for the hotel quarantine accommodation costs. The fee is a fixed contribution to the overall quarantine costs, currently AUD 3000 for one adult. The guests were also informed that they would not be charged more if they were required to stay in quarantine longer than 14 days, due to unexpected circumstances.

Most arrivals into Australia have been hotel-quarantined, including in apartment hotels. Consequently, the rising concerns about the quarantine system were directly linked to accommodation within hotels. The concerns regarding mandatory hotel quarantine relate to the system's effectiveness and feasibility-several travelers who arrived in the country tested positive for COVID-19-. For example, 681 returned travelers in NSW tested positive between June 2020 and May 2021 while in quarantine hotels [5]. Travelers identified as having acute or ongoing health care needs and who tested positive for COVID-19 were referred to specialized health accommodation, while others were directed to quarantine hotels [6]. One study reported quarantine hotels' "notable risk of failure" when reviewing the Australian hotel quarantine approach [7]. According to review data, by February 2021, the quarantine hotel system had failed seven times, with one failure causing over 800 deaths [7].

Australia has experienced the COVID-19 Delta variant since May 2021, which health experts have defined as more infectious than previous variants, with transmission possible during quick contact [8]. Increasing concerns have led to questions about the effectiveness and feasibility of quarantine hotels. Furthermore, Sarah Nickson's [9] inquest into the UK government's arrangement for a partial hotel quarantine system applies globally to the overall hotel quarantine system. It noted the absence of an appropriately skilled workforce running hotel quarantine, and failures to maintain the physical and mental health needs of those people within the quarantine. The current study has investigated the Australian quarantine experience, highlighting the more than 20 months of providing mandatory quarantine services.

\section{Research Framework: Quarantine Hotels}

The COVID-19 pandemic has spatial implications of social isolation, with policies and regulations that prioritize social distancing. The hybridization of domestic environments and quarantine hotels is a result of these implications. The National Review of the Hotel Quarantine Report [4] mentions that hotel quarantine is challenging to endure, and requires expensive resources and a highly specialized workforce.

Due to legislated requirements, a traveler arriving in Australia goes through "a quarantine journey", which is authorized and controlled by each state with slight variations. Arriving guests are informed about the quarantine process applied to them prior to their arrival. Travelers are guided to allocated buses, which operate at a maximum of half capacity, with police generally in charge of movements between airports and hotels. After arrival at a hotel, guests are guided to the foyer in small groups for a limited time, then escorted to their hotel rooms [4]. Hence, the quarantine journey, which requires 14 days, is limited to the hotel room space as per legislative requirements, as presented in Figure 1. Guests were informed about what to expect during their stay, shared as a brochure prepared by the Australian government: "Getting Ready for Quarantine". The document included the information that hotels would provide three meals a day, varying across different facilities. In addition, the guests could expect basic $\mathrm{Wi}-\mathrm{Fi}$, a telephone and television; however, laundry services would be at their expense. Due to COVID-19 measures, the rooms would not be cleaned during their stay. Smoking was not allowed in the rooms, and guests in quarantine would not be able to smoke. The document's first page prepared the guests by mentioning that "quarantining in a hotel will be different from your normal experience of staying in a hotel", and could be challenging [5]. 


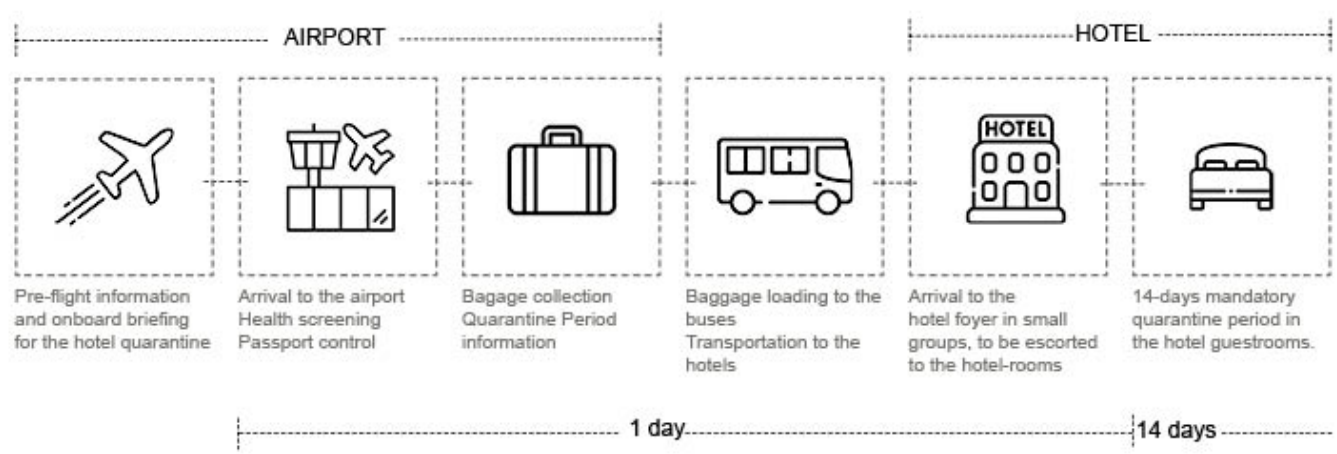

Figure 1. Process of the "hotel quarantine journey", as illustrated by the authors.

From an architectural point of view, the emerging discussions regarding the quarantine hotel space have focused on social distancing and contact-free systems, which mainly affect hotels' gathering and meeting places [10]. Initially, the idea of transforming hotels into quarantine hotels might be considered a responsive solution, considering the devastating impact of COVID-19 on the hospitality sector and shortages of governmental quarantine institutions and facilities. The adaption of hotels for quarantine use under exceedingly variable demands has shifted the priorities of hotel management. Touristic needs have been displaced, and the allocated meaning of "safety" correlates with hygiene. Providing a safe environment for employees and guests through contactless services and increased hygiene control has become the new priority [11].

Safety measures for mandatory quarantine comply with anti-epidemic and disinfection standards, and are validated by new appreciations of hotel services. Some "modified" safety measures include hygiene and protection, customer waiting-time reorganization, staff COVID-19 training, service-space reorganization, and further technology requirements [12]. Guests staying at hotels for their isolation period are obligated not to leave their allocated rooms for 14 days. Many common areas, including social facilities such as sports centers and swimming pools, are not available to guests. The hotel foyer is primarily closed to public access, and hotels organize locations to collect deliveries outside of the hotel. The reception area, which hosts both check-in and check-out services, has been suggested to move to different hotel areas to minimize infection risks. Each day, a regular schedule should be applied to disinfect any potentially contaminated surface, including elevators, lobbies, hotel entrances, and door handles. In addition, guestrooms must be cleaned and disinfected for each user change-over, and garbage collection must be organized outside the rooms [13].

The design, management, and delivery of hotel quarantine facilities are significant in preventing the spread of the virus from travelers arriving with COVID-19. Similar to many other countries, the Australian health system has had no experience with such severe pandemics. The evolving system from the previous two years has effectively been an emerging model, mainly as there were no previous systems for investigating the long-term impact on people from experiencing quarantine. The National Review of Hotel Quarantine Report [4] reported that there had been a lack of information about user experiences in the quarantine system. While many people reported their experience as acceptable, complaints included a lack of fresh air, poor quality accommodation, room size, food, and health support. The report also noted that some complaints had been made against police behavior, the requirement to quarantine, and traveler costs.

Over the last two years of global COVID-19 experience, research has been mainly focused on social-distancing requirements and how to adapt the spaces accordingly. The primary concern was preventing the spread of the virus, which required urgent solutions. Limited studies explore the impacts of the hotels' transformation into quarantine hotels on travelers, as they primarily focus on the hospitality industry perspective $[2,11,14,15]$.

Teng et al. [14] discussed the idea of the "quarantine hotel" as a model for "corporate social responsibility" within public health and its impact on hotel employees and stake- 
holders. Choi and Choi [2] conducted a qualitative study on employees and stakeholders of quarantine hotels in South Korea. Based on hotel employees' statements about their work, their findings overlap Goh and Baums' [11] investigation outcomes.

In both studies, employees were proud of working in a meaningful way to make the world safer. However, they had concerns about the hotels' brand image post-COVID-19 and were under workplace stress due to their fear of being exposed to COVID-19 [16].

Two studies $[17,18]$ were conducted with the travelers who stayed in hotel quarantine. Wu et al. [17] investigated the relationships between psychosocial risk, relationship quality, need for cognition, and quarantine intentions. They reported that, while depression, anxiety, and stress negatively influenced satisfaction with quarantine hotels, trust and intimacy positively impacted satisfaction. Wang et al. [18] explored the travellers' perceptions of the services provided in hotels under quarantine in China and Taiwan and their revisit intentions. Essentially, the quarantine system has been the primary focus of research. No studies have investigated the use of hotel rooms or addressed user experiences to understand the effectiveness of quarantine hotels. Hotel rooms remain a critical feature of how rooms could be physically prepared for secondary functional demands in the future. Focusing on the hotel space and implementing an "insider" (experience-based) view through surveys, this study aims to reveal user experiences of quarantine facilities to understand the hotel adaptation process. This study aims to apply a mixed method (both qualitative and quantitative) approach for exploring the spatial adaptation from hotel room to quarantine room from the perspective of the user requirements within the Australian context.

\section{Research Methodology}

The data collected for this research is based on users' quarantine hotel experiences during mandatory isolation (14 days). Since users were not allowed to be outside their allocated guestrooms during the isolation period, the interior spaces, particularly hotel rooms, are the research's primary focus. There is limited information on how hotel guestrooms are prepared and used for quarantine purposes, as hotel management keeps details confidential. Hence, a preliminary interview was conducted with one quarantine hotel user to obtain background information. The literature was reviewed, and a survey was designed to derive two types of information:

(1) Descriptive data on participants, such as age and gender;

(2) data on hotel room experiences, such as guestroom physical conditions (for example, lighting and ventilation) and their outcomes on users' well-being during and after quarantine (Table 1). The survey questions did not include specific questions about families and their quarantine experience with children.

The survey data was collected using the UNSW online survey tool (Qualtrics), and was administrated by the authors. An online survey link was shared with hotels and hotel quarantine social media groups based in Australia. Two criteria restricted the enrolment of participants:

(1) Participants were hotel users obliged to stay in isolation for two weeks due to Australian COVID-19 health requirements;

(2) Participants were over 18 years old. The survey was available to people who had previously been quarantined and/or were in the second week of their quarantine period.

The data collected was non-identifiable as per the negligible risk review guidelines, and the UNSW Human Ethics Committee approved the 15-min survey. The participant details and hotel names were not identified during data analysis, as the aim was not to evaluate specific hotels but overall user experiences. The names of hotels functioning as quarantine facilities were kept confidential by the Australian government as a protective measurement for the hotels' reputations. 
Table 1. Questionnaire items: user descriptive properties and hotel room experience.

\begin{tabular}{|c|c|c|c|}
\hline \multicolumn{4}{|c|}{ Descriptive Properties Questions } \\
\hline $\begin{array}{l}\text { Descriptive } \\
\text { Properties }\end{array}$ & Question Type & Respons & \\
\hline Age & Multiple-choice question type & $\begin{array}{l}18 \text { to } 24 \\
25 \text { to } 34 \\
35 \text { to } 44 \\
45 \text { to } 54\end{array}$ & $\begin{array}{l}55 \text { to } 64 \\
65 \text { to } 74 \\
75 \text { years and over }\end{array}$ \\
\hline Gender & Multiple-choice question type & $\begin{array}{l}\text { Male } \\
\text { Female }\end{array}$ & $\begin{array}{l}\text { Non-binary } \\
\text { Prefer not to say }\end{array}$ \\
\hline \multicolumn{4}{|c|}{ Hotel Room Experience Questions } \\
\hline $\begin{array}{l}\text { Please rate the importance of } \\
\text { the item to your well-being. }\end{array}$ & $\begin{array}{l}\text { Matrix table, } 9 \text { items: } \\
5 \text { Likert Scale: Not at } \\
\text { all-Extremely Important }\end{array}$ & \multicolumn{2}{|c|}{$\begin{array}{l}\text { Colour and pattern of the room, } \\
\text { Maintenance of the room, cleanliness } \\
\text { Ventilation system, } \\
\text { Acoustics-noise control, } \\
\text { Natural lighting, } \\
\text { Artificial lighting, } \\
\text { Room temperature control, } \\
\text { Openable window } \\
\text { View of the room }\end{array}$} \\
\hline $\begin{array}{l}\text { Please rate your experience at } \\
\text { the hotel quarantine. }\end{array}$ & $\begin{array}{l}\text { Matrix table, } 3 \text { items: } 1 \text { item is } \\
\text { repeated. } \\
5 \text { Likert Scale: Strongly } \\
\text { disagree-Strongly agree }\end{array}$ & \multicolumn{2}{|c|}{$\begin{array}{l}\text { I feel almost at home in my hotel room during quarantine. } \\
\text { Staying in the hotel for quarantine has not affected my future } \\
\text { experience in hotels. } \\
\text { I would like to return to this hotel for a holiday in the future. }\end{array}$} \\
\hline \multicolumn{2}{|c|}{$\begin{array}{l}\text { Could you share any positive factors about the room affecting } \\
\text { your well-being? }\end{array}$} & \multicolumn{2}{|c|}{ Open-ended question (Text entry) } \\
\hline \multicolumn{2}{|c|}{$\begin{array}{l}\text { Could you share any negative factors about the room affecting } \\
\text { your well-being? }\end{array}$} & \multicolumn{2}{|c|}{ Open-ended question (Text entry) } \\
\hline
\end{tabular}

The quantitative data were analyzed by statistical methods, while quantitative methods were used to evaluate the open-ended questions. The detailed approach to each method is described in Section 4. At the end of the survey, participants were asked if they would like to share photographs of their hotel room. Some of the images referred to in this paper were shared by the users through the survey, while others were shared publicly through the quarantine hotels social media groups. Traditional and digital media sources were checked within media releases and news commentary to expand the quarantine hotels information base. In addition, social media posts shared by individuals staying in hotel quarantine and blog posts on digital platforms were reviewed to identify quarantine hotels.

\section{Data Analysis}

The survey was available between June and September 2021, and there were 54 respondents from various capital cities in Australia: Perth, Brisbane, Sydney, and Melbourne. The collected data is discussed in the following two subsections: descriptive data, and user experience data.

\subsection{Descriptive Data}

All participants answered the descriptive questions. Of the 54 participants, 15 were male $(27.78 \%)$, and 39 were female $(72.22 \%)$. The median age group was $35-44$ years old, constituting $33 \%$ of the respondents, followed by $45-55$ years old (27\%) (Figure 2). 


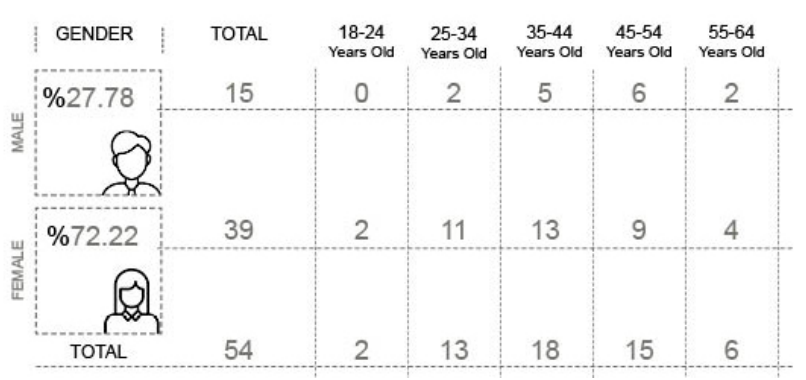

Figure 2. Descriptive data of survey respondents.

\subsection{User Experience Data}

This survey data referred to the physical conditions of the guestrooms, and was analyzed using both quantitative and qualitative methods. The responses were analyzed through statistical methods based on quantitative data. The results were analyzed using qualitative methods, such as evaluating open-ended questions and images shared by the participants. SPSS 24.0 software was used for statistical analyses. First, principal component analysis (PCA) was conducted. Further analyses, such as a one-way analysis of variance (ANOVA) and t-tests, were performed to determine links between descriptive characteristics and items supporting well-being. Table 2 outlines the number of dependent variables from the dataset ( 9 questionnaire items related to well-being), which was reduced to independent variables (three-factor items), according to the 54 respondents.

Table 2. Component loading of each factor and questionnaire item.

\begin{tabular}{|c|c|c|c|c|c|}
\hline \multirow[t]{2}{*}{ Factors } & \multirow[t]{2}{*}{ Questionnaire Items } & \multicolumn{3}{|c|}{$\begin{array}{l}\text { Component Loading } \\
\text { the Contribution of Each Variable on Principal Components }\end{array}$} & \multirow{2}{*}{$\begin{array}{c}\text { Rotation Sums of } \\
\text { Squared Loadings } \\
\% \text { Variance }\end{array}$} \\
\hline & & 1 & 2 & 3 & \\
\hline \multirow{4}{*}{ View } & The view of the room & 0.776 & -0.114 & & \multirow{4}{*}{24.40} \\
\hline & $\begin{array}{l}\text { Colour and pattern use } \\
\text { in the room }\end{array}$ & 0.722 & 0.322 & & \\
\hline & Acoustics-noise control & 0.658 & 0.328 & 0.209 & \\
\hline & $\begin{array}{l}\text { Control of the room } \\
\text { temperature }\end{array}$ & 0.584 & 0.413 & -0.131 & \\
\hline \multirow[t]{2}{*}{ Cleanliness } & $\begin{array}{l}\text { Maintenance of the } \\
\text { room-cleanliness }\end{array}$ & 0.195 & 0.798 & & \multirow[t]{2}{*}{19.58} \\
\hline & Artificial lighting & & 0.783 & 0.158 & \\
\hline \multirow{3}{*}{ Ventilation } & Ventilation system & -0.130 & 0.303 & 0.799 & \multirow{3}{*}{21.31} \\
\hline & Operable window & & & 0.745 & \\
\hline & Natural lighting & 0.483 & -0.153 & 0.673 & \\
\hline
\end{tabular}

Statistical analysis has indicated the variable questionnaire items named as View, Cleanliness, and Ventilation factors. Since Cronbach's alpha level was higher than 0.7, each factor was considered reliable, and these key factors were identified as explaining $65.3 \%$ of the data structure variance. Finally, factor analysis was undertaken to establish the underlying data structure with Varimax rotation (oblique solution) to determine if the correlation between the factors was zero.

T-test analysis of the gender-based factors, as mentioned earlier, has not shown a statistically significant difference. However, a statistically significant difference $(p<0.05$; $95 \%$ confidence intervals) was recognized among age groups (45+ and 18-35 years, see Table 3). The one-way ANOVA test results have presented those respondents over 45 years 
old considered View to be a more significant factor affecting their well-being than the respondents under 35 years old.

Table 3. The results of the one-way ANOVA test.

\begin{tabular}{cccccccc}
\hline \multicolumn{2}{c}{ Dependent Variable } & \multicolumn{2}{c}{$\begin{array}{c}\text { Mean } \\
\text { Difference (I-J) }\end{array}$} & Std. Error & Sig. & \multicolumn{2}{c}{ 95\% Confidence Interval } \\
\cline { 5 - 9 } & & $18-34$ & 1.116 & 0.335 & 0.005 & 0.300 & Lower Bound \\
\hline View & $45+$ & 18 Upper Bound & 1.931 \\
\hline
\end{tabular}

\section{Results and Discussion}

Due to the variety and interrelationships of the outcomes, each is presented under the subheadings: critical sources of well-being during quarantine, fundamental spatial needs from a quarantine hotel room, and impacts of quarantine experience on future use followed by the relevant discussions.

\subsection{Critical Sources of Well-Being during Quarantine}

Participants were asked to rate the key sources supporting their well-being during isolation on a 5-point scale (1: Not at all, 5: Extremely important). The mean scores of each item supporting participants' well-being are presented in Figure 3. Among the nine listed items, the three highest-scoring factors were: (1) operable window (4.7), (2) ventilation (4.5), and (3) natural lighting (4.3). The difference between the highest score (operable window, 4.7 ) and the lowest (color and pattern of the room, 2.4) was 2.3 points. The second-lowest score was for artificial lighting (3.4).

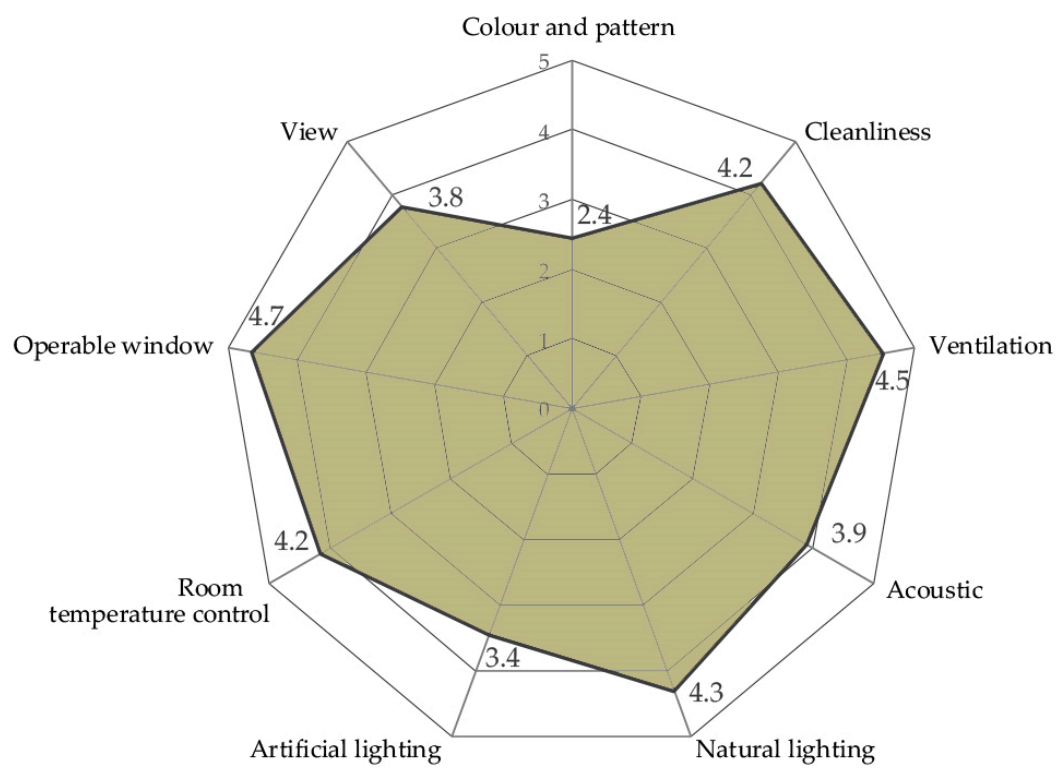

Figure 3. Mean scores of wellbeing-related items (1: Not at all, 5: Extremely Important).

Participants were asked to state the positive and negative factors of their hotel room experience in terms of their well-being. A total of 36 out of 54 respondents $(67 \%)$ provided comments on domestic environment factors (hotel room) that affected their well-being. Word clouds were generated from the open-ended comments using a free online word cloud generator [19], in which frequently occurring words are shown in larger fonts. The keywords "balcony, large, room, space, view" were commonly stated as positive factors, while "air, fresh, window, room, food and balcony" were among the negative ones (Figure 4). 


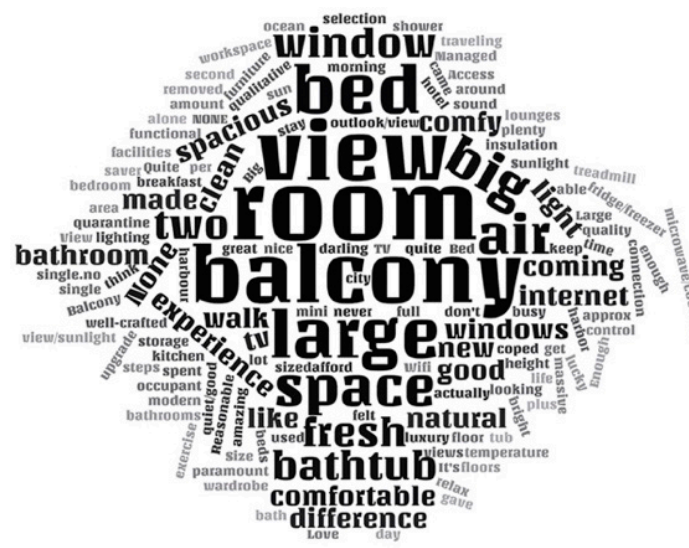

Positive factors

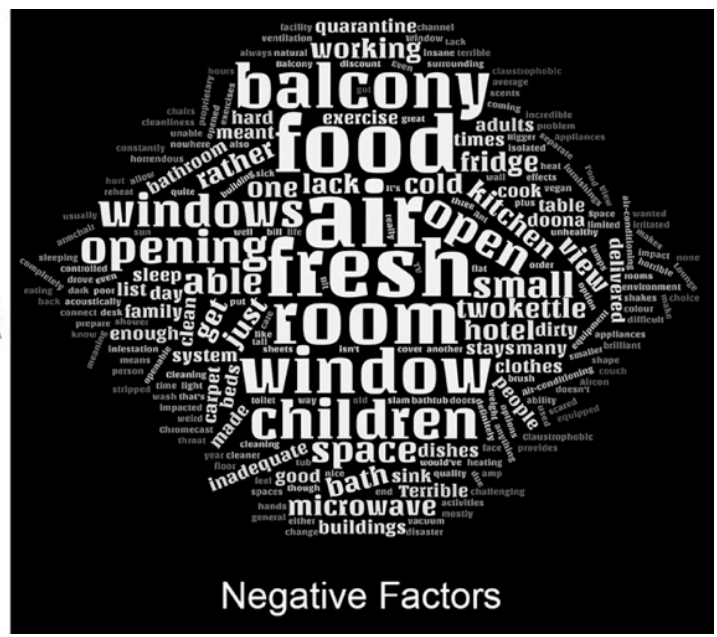

Negative Factors

Figure 4. Positive and negative factors affecting the participants' well-being (Source: Wordclouds Generator).

The repetition of keywords confirmed the consistency of the participants' answers. For example, while having a balcony was a highly positive factor, the lack of an open area to access fresh air was mentioned negatively. When juxtaposed, the results are consistent with the mean scores of the items supporting well-being in the survey (Figure 3).

\subsection{Spatial Requirements for Quarantine Hotel Rooms}

The survey was completely anonymous, and did not aim to identify any hotels but focused on the users' experiences. As most arrivals to Australia have been quarantined in hotel rooms, two standard hotel room sizes were defined to outline the survey outcomes based on guests' answers to the open-ended questions. A standard double room has an en suite bathroom, a double bed with a small workspace. A superior double room includes enough space for two twin/double beds, with a large shower space/bathtub. When the second bed is removed from the room, it creates an area for exercising, as mentioned among the positive factors. Figure 5 compares the advantages and disadvantages of the two different standard hotel rooms according to the responses to the survey's openended questions.

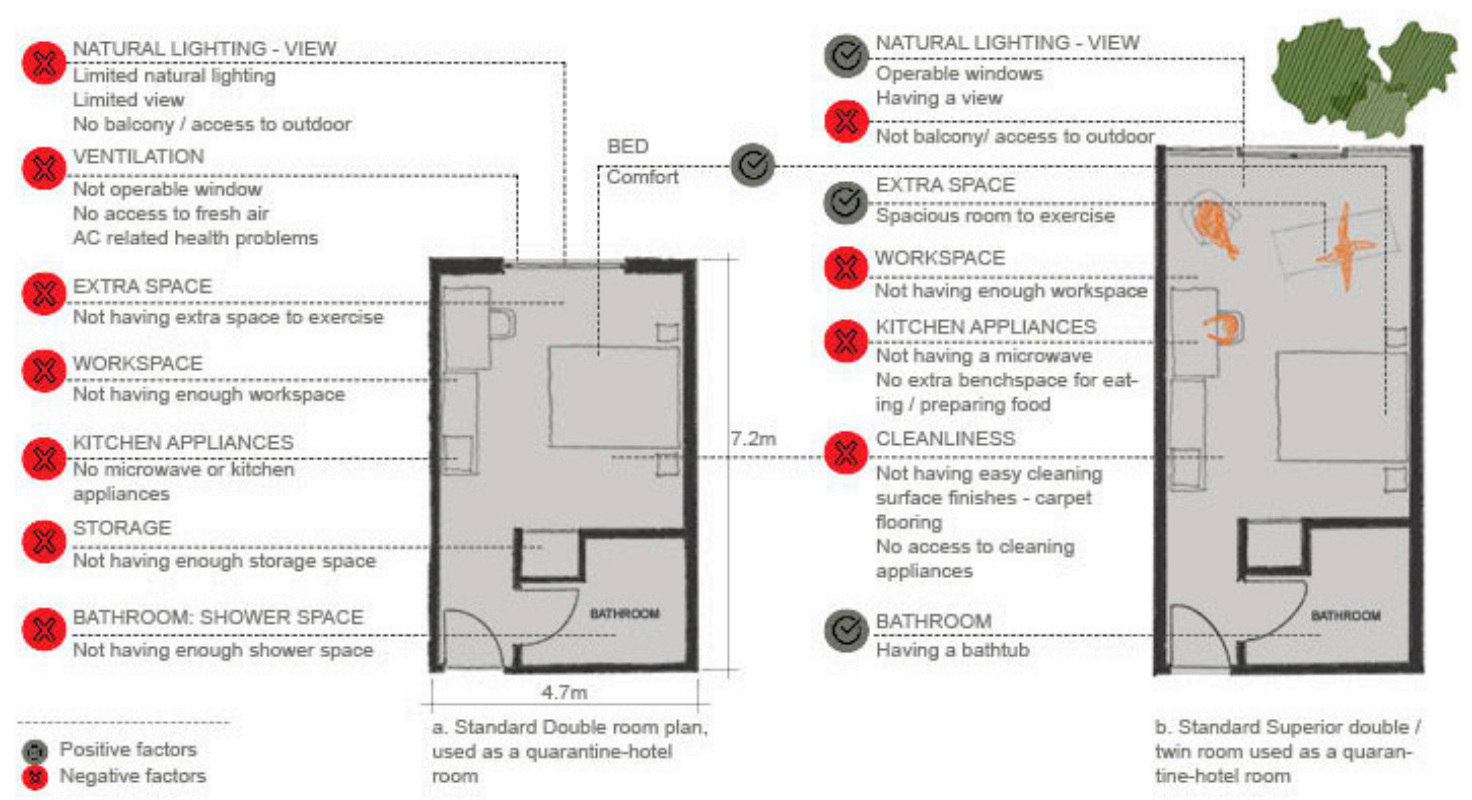

Figure 5. Positive and negative factors of two standard hotel rooms. 
The quantitative results presented in Table 2 and Figure 3 were combined with this qualitative data to determine the sub-sections as "spatial requirements". These subcategories are defined as: (1) View and ventilation (including 'outdoor access'), (2) additional space and appliances, and (3) cleanliness and hygiene.

\subsubsection{View and Ventilation}

"View" was the main contributing factor in the PCA (explaining $24.40 \%$ of the variance) (Table 3). Open-ended comments from 16 out of the 36 participants acknowledged similar findings regarding the substantial contributions of natural light and a view:

"A view, view, Reasonable outlook/view of the city. There were large windows looking over the harbor. That was where I spent most of my time in quarantine."

"Love the sun coming in through the window; sunlight coming in, full-height window; a lot natural lighting and big windows."

While some guests had access to fresh air, others spent the whole isolation period in a room that was fully air-conditioned (AC). Due to hotel safety issues and to prevent energy losses, buildings are primarily designed with airtight envelopes that do not permit natural ventilation and rely on conventional building heating, ventilation, and air conditioning (HVAC) systems [20]. The lack of view and access to an outdoor environment had an overwhelming impact on guests, causing dissatisfaction and stress. Zhuo and Zacharias [21] mentioned that the loss of an outdoor environment also entails the loss of its stress-reducing effects and the associated lowered risk of psychosomatic symptoms. In addition, long-term exposure to an AC environment might have affected people's responses to stimuli such as air temperature, humidity, and airspeed fluctuations, weakening their natural adaptive mechanisms and thermal adaptability [22-24]. Uena and Ohnaka [25] found that significant variations in ambient temperature and relative humidity between indoors and outdoors might act as environmental stressors. Long-term exposure to an AC environment may influence diurnal salivary cortisol levels. The findings of Buonocore et al. [22] and Yu et al. [26] showed that long-term exposure to AC affected participants' thermal sensations. However, these studies involved subjects spending more than $10 \mathrm{~h}$ in an air-conditioned room, with no relevant studies investigating the impacts of exposure on human physiology and health for more extended periods. In quarantine hotels, guests are obliged to stay in the same room for two weeks, which might cause significant responses compared to the previous limited AC studies. The participants complaining about not having an operable window reported the atmosphere as "claustrophobic" (Figure 6). The following complaints referred to the lack of fresh air due to the lack of an operable window or balcony:
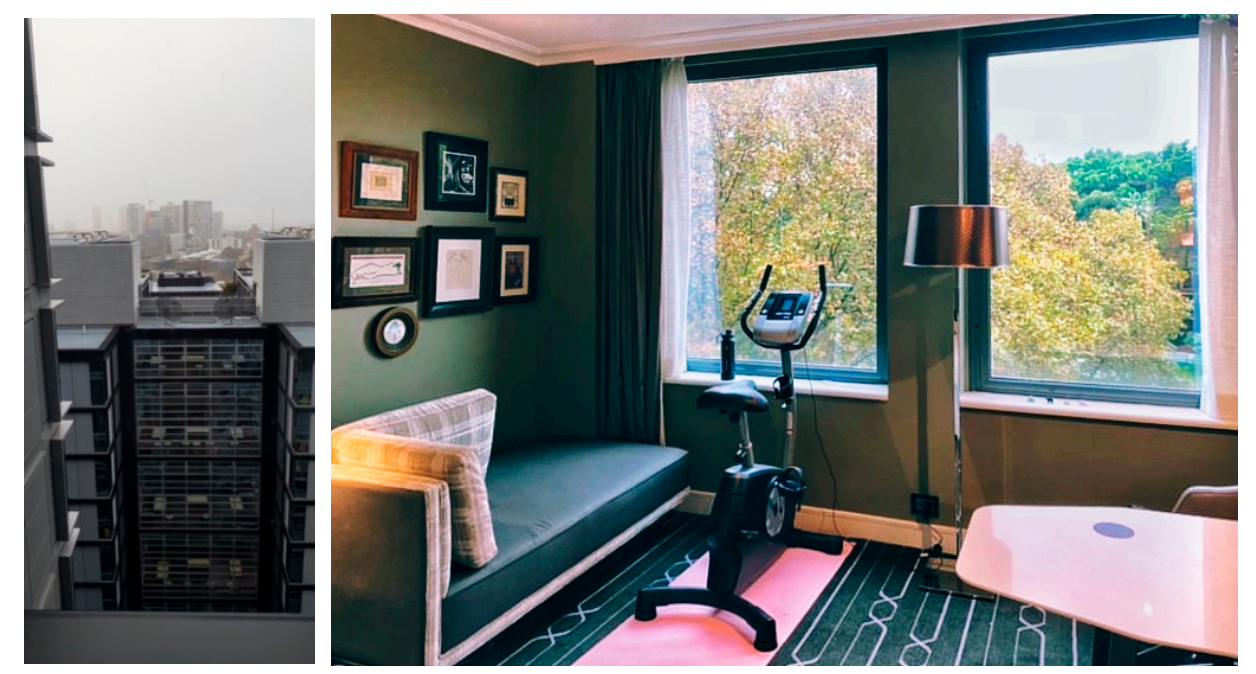

Figure 6. Two photos shared by survey participants showing the view from and window of their quarantine hotel rooms. 
"No fresh air was incredibly challenging."

"The lack of opening windows and fresh air drove me insane. It was horrible."

"No openable window, no balcony, no room for exercise, tall buildings surrounding so limited natural light air-conditioning (made me sick)."

Several open-ended comments from participants (8 out of 36) related to hotel room features that positively affected their well-being overlapped with the mean scores of the importance of items listed in the questionnaire. The highest mean score (4.7) was found for an operable window. Window / balcony was a highly mentioned keyword among the open-ended comments (Figure 4). Having a balcony supported participants' well-being during their stay in isolation. A balcony was described as a "life-saver" by one participant, and another stated his preference for a balcony as:

"Not being able to open the windows did make it feel claustrophobic at times, I would rather have had a smaller room with a balcony."

Several supportive comments from participants are noted below:

"Having a balcony and ... with an ocean view made a massive difference."

"The balcony was a life-saver for air and a view."

"It has a balcony; I don't think I would have coped with no fresh air."

"The balcony and view have been amazing with the fresh air."

"There were two large balconies. We had fresh air and nice our breakfast there."

Post-COVID-19 studies support the positive impact of a private outdoor environment on mental health and well-being. For instance, Grigoriadou [27] mentioned that balconies could significantly improve health during the confinement period. Francisco et al. [28] provided statistically significant results showing that having an outdoor exit in the house (for example, garden, terrace) contributed to psychological and behavioral symptomatology levels. In contrast, research by Zhuo and Zacharias [21] did not support this outcome. According to their study results, although a balcony or private outdoor space connects people with the environment, having a balcony did not significantly improve the sense of life quality; instead, it was negatively correlated with mental status. Considering that this study focused on domestic space, the conflict in the results could be linked to the different environmental settings. Moreover, the same study highlighted that the daylight levels within a housing unit are a positive factor for well-being, which overlaps with the results found in the current study. Daylighting (natural lighting) was the third strongest contributor to participants' well-being during isolation (Figure 2, Table 2, grouped under PCA Factor 3). Another study conducted by Asim et al. [29] focused on students staying in hostels, which revealed that a quality view from a window and a view of greenery and the sky positively influenced mental health. Accordingly, a view of exterior greenery provides positive feelings of escape and leads to higher perceived restorative quality and, in turn, lower depressive/anxiety symptoms [30].

\subsubsection{Additional Space and Appliances}

The guestroom sizes in the hotels ranged between 19 and $55 \mathrm{~m}^{2}$, depending on the hotel. A mandatory stay in the same room requires a better spatial arrangement, such as more space to exercise or access to essential kitchen appliances. The support provided by the health organizations, as well as the hotels, encouraged guests to engage in building a routine that was effective against "mental fatigue, feelings of isolation, and vulnerability" [4] (p. 27). Several complaints detailed not having a space to relax/exercise or kitchen facilities, which limited guests' opportunities to structure a daily routine. A total of 11 of 36 people stated that having more space and a bright room positively affected their well-being. On the other hand, ten people highlighted the adverse effects of lacking extra space and having a darkened room with less access to the light (Figure 6). Social media 
posts show that users had to find alternative ways to exercise and eat a balanced diet due to the lack of essential appliances or furniture. For example, Figure 7 shows using an iron to warm up food, and a sofa was rotated to function as a dining table. One user sharing the kettle photo, shown in Figure 8, suggested other hotel quarantine guests boil the jug with the lid open to add moisture in the air (due to the lack of fresh air). Another user's suggestion was to use the bin as a laptop stand for work.
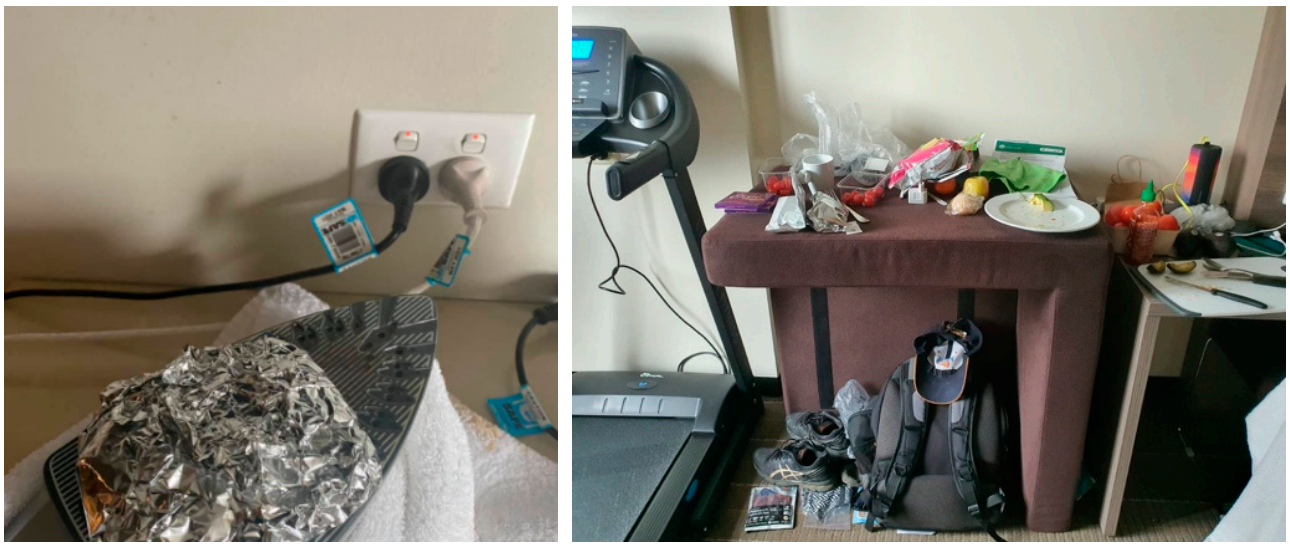

Figure 7. Alternative uses for existing appliances and furniture shared in social media groups: iron to warm-up falafels, and sofa used as a dining table.
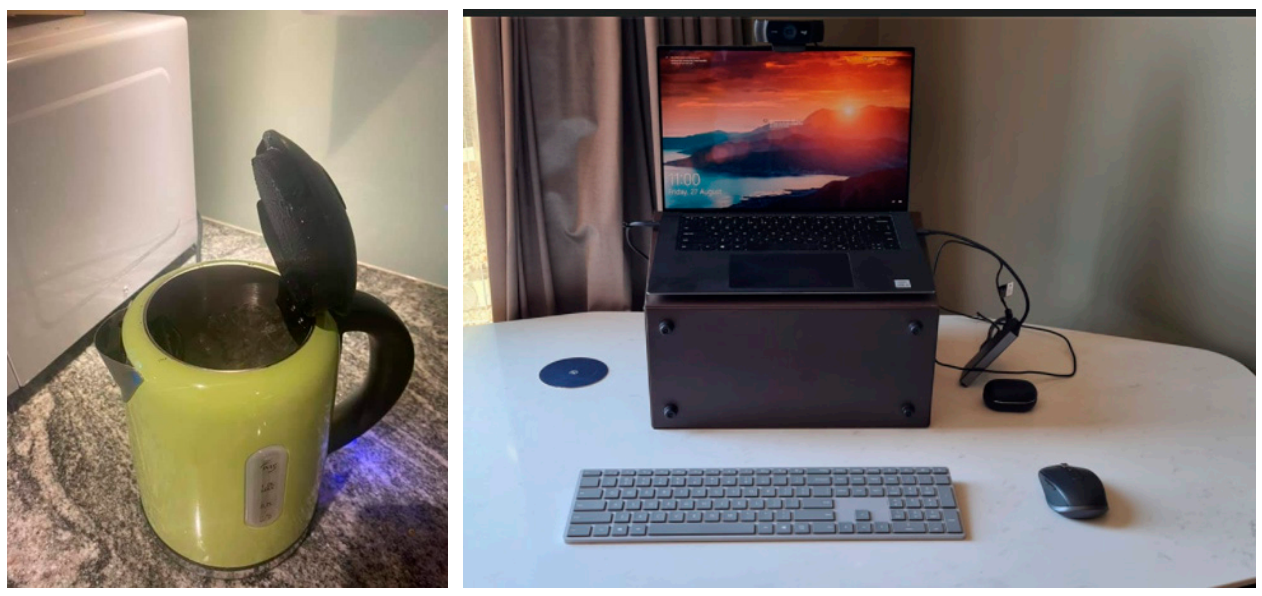

Figure 8. Alternative uses for existing appliances and furniture shared in social media groups: kettle used to humidify the hotel room environment, and trash bin as a laptop stand.

The responses about having more space/a spacious rooms were linked to the availability of exercise by seven guests, as one commented: "two beds for one person meaning no floor space". It should also be noted that only 36 of 54 people preferred answering the questions regarding the positive aspects of their quarantine stay, while two answered as "None". The rooms used for quarantine facilities had an en suite bathroom with a shower and/or a bathtub. Having a bathtub or a larger shower space was mentioned as a positive factor by seven of 36 survey respondents:

"Having a large space with a view/sunlight, a workspace, an area where I could relax, and a bathtub made a big difference to my experience."

"Clean and qualitative bathroom."

Three people stated that lacking a bathtub was a negative factor, and one comment was, "No bath, which isn't a problem for me, but my two-year-old is scared of the shower!". 
One of the other factors affecting well-being was the kitchen or kitchen appliances, as mentioned by seven survey participants (Figure 9). While some guestrooms included essential kitchen appliances for cooking or heating food, some hotels only provided delivery services. For users without a kitchen area, this was stated resoundingly as a negative factor:
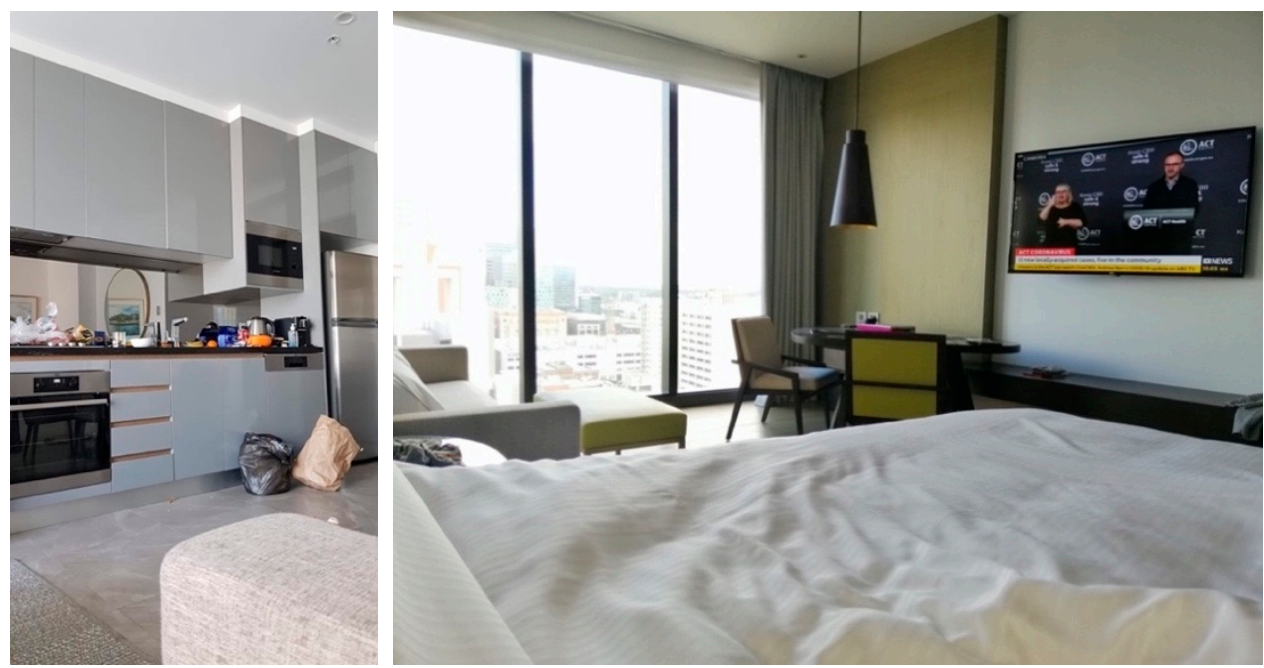

Figure 9. Two different types of quarantine hotel rooms, photos shared by survey participants.

"The bathroom sink is difficult to wash dishes or clothes in."

"No kitchen facility to prepare food for the children, and what was delivered was inadequate."

"No means to reheat food which was always cold. Appliances were stripped, so I do not know if this hotel usually provides a microwave."

"No microwave meant constantly eating cold food and made food choice hard."

"The food was really good but unhealthy, so I would have rather have had the option to have a kitchen (rather than just a microwave and kettle) and order my own food to cook and not get food delivered and get a discount on the bill. I definitely put on weight during quarantine even though I was working out three times a day."

The findings in the current study on travelers' unique needs in guestrooms overlapped with the study by $\mathrm{Wu}$ et al. [17]. They proposed redesigning room services and amenities (such as dance mats with related programs, Yoga mattresses, relevant TV applications, and 24-h psychological counseling telephone service) to meet guests' psychosocial needs and reduce their real and perceived psychosocial risks.

\subsubsection{Cleanliness and Hygiene}

"Cleanliness" emerged as the second leading contributing factor in the PCA (explaining $19.58 \%$ of the variance). Additionally, cleanliness was rated as one of the essential key sources of well-being during isolation (mean score $=4.2$ ). As most of the hotel rooms' flooring was carpeted, there were concerns about cleanliness and hygiene, particularly when a guest tested COVID-19 positive. As Figure 5 shows, a standard double room with a small non-operable window would not provide enough comfort for guests' well-being, while a superior room might maintain well-being. Hotel apartments and hotel rooms with controlled outdoor access and/or quarantine facilities would support a higher level of satisfaction.

Cleaning and disinfecting surfaces reduce infection risk, as the COVID-19 virus can be found on surfaces. For that reason, all facilities were obliged to follow standard practices and appropriate regulations for minimum cleaning and disinfection standards [31]. According to the Environmental Protection Agency (EPA) [32], cleaning surfaces with soap and water is advisable to remove germs and dirt. However, there have also been warnings 
about using disinfectants around people with asthma, as they could trigger an asthmatic attack. UV lights or ozone generators might be used for disinfection; however, the EPA warns that they are risky or ineffective. Due to restrictions in the hotel quarantine system, hotel room cleaning could only occur between 14-day-isolation periods. Only the participants would occupy the hotel room during the isolation period. However, cleanliness is an essential need and a health concern, particularly for people with allergies and asthma (Figure 10).
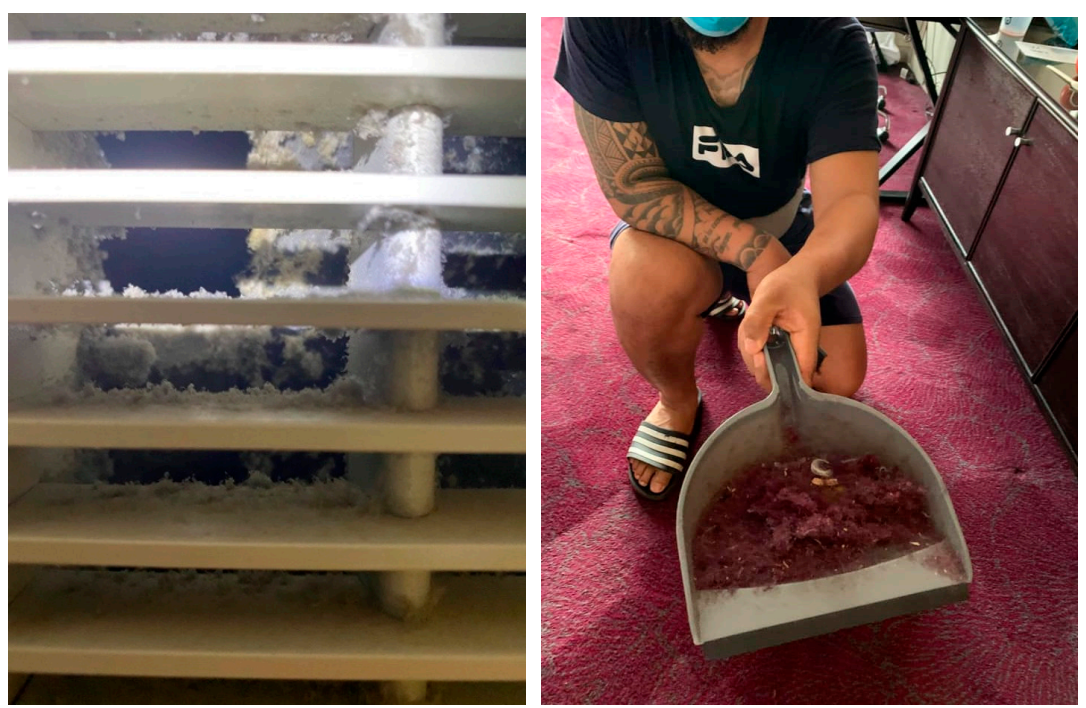

Figure 10. Maintenance of the room cleanliness, photo shared by quarantine hotel users in social media groups.

In addition, there were hotel rooms with no natural ventilation or any cleaning equipment so that the user could self-respond to this fundamental need. Maintenance of room cleanliness was one of the concerns evident in participants' responses to the negative factors, for example:

"Carpet and general room cleanliness below average"

"It is very small. There is no cleaning equipment like toilet brush or way to clean carpet.

Cleaning dishes in bathroom sink and clothes in the bathtub is not great."

"Doona had no doona cover-just flat sheets."

"No vacuum cleaner or other appliances to clean the room."

\subsection{Impacts of Quarantine Experience on Future Use}

Previous research indicates that the immediate needs of a hotel-room stay are safety and security, physical well-being, communication/interaction, and personal-physical space [33]. Hotels provide technical equipment and in-room facilities for their guests, as well as security. By addressing such fundamental needs, hotels aim to make guests "feel at home" [33]. When used as a quarantine facility, a high level of security is provided, and guests mentioned "security guards waiting at the hotel hallways". The meaning of security reverses from protecting guests from outside disturbances to preventing travelers from leaving their rooms during their isolation.

Respondents were asked whether they agree or disagree with the following three statements about their hotel quarantine experience concerning its future impact:

"I feel almost at home in my hotel room during quarantine."

"I would like to return to this hotel for a holiday in the future."

"Staying in the hotel for quarantine has not affected my future experience in hotels." 
The mean scores of the respondents' answers to these three statements are shown in Figure 11. The results show that participants were unwilling to return to the hotel where they spent quarantine for a holiday (the mean score is 2.5). This result is consistent with Hao et al. [3], who concluded that the guests' negative connotations (unpleasant memories) might deteriorate their hotel opinions. An acknowledged fear of being recognized as a "quarantine center" rather than a hotel was noted as a concern in a study by Mujambar [15]. Choi \& Choi [2] also highlighted the negative brand image associated with "pandemic", "death", and "fear", with a potential concern for future customer preferences. According to the questionnaire results, staying in a quarantine hotel did not affect guests' future hotel preferences, as the mean score for that statement was 2.9. Another question from the survey inquired whether the guests felt at home during their stay (mean score $=2.1$ ).

I would like to return to this hotel for a holiday in the future.

Staying in the hotel for quarantine has not affected my future experience in hotels.

I feel almost at home in my hotel room during quarantine.
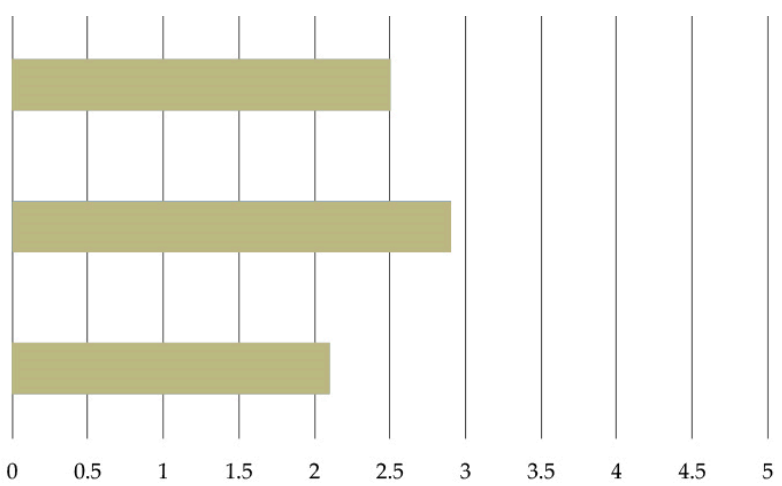

Figure 11. Mean scores of the hotel quarantine experience (1: Strongly disagree, 5: Strongly agree).

Despite the answers to open-ended questions, such as "we could never afford to actually stay in a hotel room like that, so it felt like a luxury experience", the lowest mean score for this statement indicated how unpleasant an experience the participants had during their stay in quarantine. Wang et al. [18] proposed that hotel services be fully prepared to provide unique services, such as coordination with the epidemic prevention department, education and training of service personnel, and provision of clear residential instructions to encourage customers to revisit the hotel during standard times.

\section{Conclusions}

Previous research reports that hotel guests' practical in-room requirements differ when hotel rooms function as quarantine facilities. The adaptation of hotels for hosting people during mandatory isolation was an immediate response to COVID-19-related spatial demands. The rooms could not be prepared in such a short time to adequately provide for the well-being needs of people isolated for 14 days. The knowledge gained from the quarantine hotel experience suggests that future spatial needs of such quarantine environments should include supporting the guests' well-being. The current study aimed to gain insider details by engaging with guests who had experienced hotel quarantine rather than with decision-makers or hotel administrators. Research could not be undertaken on-site due to COVID-19 restrictions. However, 54 anonymous participants shared their collective insights using online survey tools. Positive and negative conditions affecting the guests' well-being were collated and analyzed. Several prioritized requirements were identified, including the need to access the outdoor environment, a view as a connection with the outdoors, and the physical need for fresh air.

The quality of the hotel depends on its availability and location, which can result in different experiences. Access to an outdoor balcony and rooms large enough for other facilities (such as exercise and cooking) creates users' imbalanced experience. In contrast, the positive and negative factors across a diverse collection of hotel quarantine facilities remained consistent. While some survey participants claimed a balcony was a "lifesaver", the lack of access to the outdoors was listed as a negative aspect by participants 
staying in a room with no balcony/view/access to fresh air. Evidently, access to the outdoor environment via a balcony or operable window is an acute and fundamental requirement for participants. In addition, factors such as the cleaning of the hotel room remain unresolved when hotel rooms function as quarantine facilities. While controlling the spread of disease during a pandemic is the a priori health concern, room cleanliness, mainly of surfaces such as carpets, should not be underestimated regarding the quarantine system's long-term effects on people. Hotel rooms should be reorganized to optimize travelers' well-being if there is ever such a requirement for hotel facilities again. Hotels not providing these fundamental spatial needs should not function as quarantine facilities due to the inherent long-term health consequences. Following increasing concerns about future epidemics or global pandemics, governments should plan quarantine facilities for such needs. Additionally, the respondents' replies showed they were unwilling to return to a hotel where they spent their quarantine, raising further questions about the future of hotels used for quarantine. Participants with access to the outdoors through balconies and/or a spacious room allowing for other facilities resulted in a distinctively more positive hotel quarantine experience which is evident in the results. The keywords stated among negative factors (for example, a lack of balcony) were balanced against the positive ones. While some survey participants claimed to have a "life-saving" balcony as a positive factor, a lack of access to the outdoors was identified as a negative factor for those participants staying in a room with no balcony/view/access to fresh air. Access to the outdoor environment via a balcony or operable window was undoubtedly an acute and fundamental requirement for the participants' well-being.

In brief, as a vital public health measure, quarantine is essential to resist the spreading of the COVID-19 virus. However, being isolated in poorly equipped facilities can cause direct and indirect physical and psychological harm [6]. There could not be any field studies performed due to COVID-19 restrictions in the hotels, thus any future studies should consider the inclusion of field experiments. In response to rising concerns about future or global epidemics, governments must learn from the COVID-19 pandemic experience and plan quarantine facilities adequately equipped for any housed citizens' safety, physical, mental, and emotional health. The participants' replies designate their unwillingness to return to the hotel where they spent quarantine days, raising secondary questions for the future of those hotels that participated as quarantine venues.

\section{Limitations}

Despite the research's significant contributions to address such an important and emerging problem, there are some limitations to be considered in this study. This paper analyses data collected from the participants who stayed in quarantine hotels in Australia. Australia is ideally placed to help understand the spatial requirements for a quarantine environment, as the hotel quarantine system was applied for arriving travelers almost twenty months ago. The study is based only on the Australian hotel quarantine system, and the survey results might vary if done in different countries. A mixed method approach in data analysis was undertaken in the study, including quantitative and qualitative methods. For quantitative analysis, the number of conducted surveys should be repeated with a larger cohort. The current study was restricted to 54 participants due to the challenges of reaching the quarantine hotels. Overall, more than ten hotels were identified and contacted as quarantine facilities. However, only one hotel agreed to share the survey with their guests in isolation. The remaining hotels either mentioned they were uncomfortable facilitating such a survey or did not reply, even when the confidentiality of the research was highlighted. Two hotels were visited in person, but our proposal to collect data onsite was rejected due to COVID-19 related restrictions. Communicating with hotels took 3-4 months, and the researchers decided to share the survey entirely online through the "hotel quarantine" social media groups. 
Author Contributions: Conceptualization, D.D. and O.G.; methodology, D.D. and O.G.; resources, D.D.; data curation, D.D.; writing-original draft preparation, D.D. and O.G.; writing-review and editing, D.D. and O.G.; visualization, D.D and O.G. All authors have read and agreed to the published version of the manuscript.

Funding: This research received no external funding.

Institutional Review Board Statement: The study was conducted according to the guidelines of the The University of New South Wales Human Research Ethics and approved by the Ethics Committee (HREAP) (protocol code HC210208 and project title “Quarantine Hotels: An Evaluation on the Hotel-Room Designs", July 2021).

Informed Consent Statement: Informed consent was obtained from all subjects involved in the survey.

Data Availability Statement: The data presented in this study are available on request from the corresponding author, Dr. Demet Dincer.

Conflicts of Interest: The authors declare no conflict of interest. The funders had no role in designing the study, the data collection, analyses, or interpretation, writing the manuscript, or publishing the results.

\section{References}

1. Deloitte. Tourism and Hotel Market Outlook Executive Summary. 2021. Available online: https://www2.deloitte.com/au/en/ pages/consumer-industrial-products/articles/tourism-hotel-outlook.html (accessed on 17 September 2021).

2. Choi, M.; Choi, Y. Employee Perceptions of Hotel CSR Activities during the COVID-19 Pandemic. Int. J. Contemp. Hosp. Manag. 2021, 33, 3355-3378. [CrossRef]

3. Hao, F.; Xiao, Q.; Chon, K. COVID-19 and China's Hotel Industry: Impacts, a Disaster Management Framework, and Postpandemic Agenda. Int. J. Hosp. Manag. 2020, 90, 102636. [CrossRef] [PubMed]

4. National Review of Hotel Quarantine Report Australian Government Department of Health. 2020. Available online: https: //www.health.gov.au/resources/publications/national-review-of-hotel-quarantine (accessed on 11 July 2021).

5. New South Wales Health Government Website Announcements. 2021. Available online: https://www.health.nsw.gov.au (accessed on 11 June 2021).

6. $\quad$ Dinh, M.; Hutchings, O.; Bein, K.; Shaw, J.; Raut, A.; Russell, S.B.; Jager, D.; Thapa, R.; Fox, G.; Edwards, J.; et al. Emergency department presentations by residents of Sydney quarantine hotels during the COVID-19 outbreak. Med. J. Aust. 2021, 214, 473. [CrossRef]

7. Grout, L.; Katar, A.; Ouakrim, D.A.; Summers, J.A.; Kvalsvig, A.; Baker, M.G.; Blakely, T.; Wilson, N. Estimating the Failure Risk of Hotel-based Quarantine for Preventing COVID-19 Outbreaks in Australia and New Zealand. medRxiv 2021. Available online: https:/ / www.medrxiv.org/content/10.1101/2021.02.17.21251946v1 (accessed on 24 July 2021).

8. Young, J. COVID Delta Variant is 'in the Air You Breathe': What You Need to Know about Sydney Outbreak Strain. 2021. Available online: https: / / www.theguardian.com/australia-news/2021/jun/24/its-in-the-air-you-breathe-what-you-need-toknow-about-sydneys-delta-covid-variant (accessed on 24 July 2021).

9. Nickson, S. Coronavirus Hotel Quarantine: Key Questions for the Government. 2021. Available online: https://apo.org.au/ node/310895 (accessed on 15 May 2021).

10. Martha, L.; Vrasida, M.; Agaliotou, C. Redefining and Redesigning Modernity in the COVID-19 Era: The Case of Xenia Hotels in Greece. In Strategic Innovative Marketing and Tourism in the COVID-19 Era: 9th ICSIMAT Conference 2020; Kavoura, A., Havlovic, S.J., Totskaya, N., Eds.; Springer International Publishing: Cham, Switzerland, 2021; pp. 233-240.

11. Goh, E.; Baum, T. Job Perceptions of Generation Z Hotel Employees towards Working in COVID-19 Quarantine Hotels: The Role of Meaningful Work. Int. J. Contemp. Hosp. Manag. 2021, 33, 1688-1710. [CrossRef]

12. Bonfanti, A.; Vigolo, V.; Yfantidou, G. The Impact of the COVID-19 Pandemic on Customer Experience Design: The Hotel Managers' Perspective. Int. J. Hosp. Manag. 2021, 94, 102871. [CrossRef]

13. Teng, Y.M.; Wu, K.S.; Lin, K.L. Life or livelihood? Mental Health Concerns for Quarantine Hotel Workers During the COVID-19 Pandemic. Front. Psychol. 2020, 11, 2168. [CrossRef] [PubMed]

14. Teng, X.; Teng, Y.M.; Wu, K.S.; Chang, B.G. Corporate Social Responsibility in Public Health During the COVID-19 Pandemic: Quarantine Hotel in China. Front. Public Health 2021, 9, 620930. [CrossRef]

15. Majumdar, R. Surviving and growing in the post-Covid world: The case of Indian hotels. Worldw. Hosp. Tour. Themes 2021, 13, 584-598. [CrossRef]

16. Teng, Y.M.; Wu, K.S.; Xu, D. The Association Between Fear of Coronavirus Disease 2019, Mental Health, and Turnover Intention Among Quarantine Hotel Employees in China. Front. Public Health 2021, 9, 557. [CrossRef] [PubMed]

17. Wu, H.C.; Chen, X.; Chang, Y.Y. Structural relationships between psychosocial risk, relationship quality, need for cognition, and quarantine intentions: The case of the quarantine hotel. Serv. Bus. 2021, 15, 1-25. [CrossRef] 
18. Wang, K.Y.; Ma, M.L.; Yu, J. Understanding the perceived satisfaction and revisiting intentions of lodgers in a restricted service scenario: Evidence from the hotel industry in quarantine. Serv. Bus. 2021, 15, 335-368. [CrossRef]

19. Word Clouds Generator. 2021. Available online: http:/ /www.wordclouds.com (accessed on 8 October 2021).

20. Aviv, D.; Chen, K.W.; Teitelbaum, E.; Sheppard, D.; Pantelic, J.; Rysanek, A.; Meggers, F. A fresh (air) Look at Ventilation for COVID-19: Estimating the Global Energy Savings Potential of Coupling Natural Ventilation with Novel Radiant Cooling Strategies. Appl. Energy 2021, 292, 116848. [CrossRef]

21. Zhuo, K.; Zacharias, J. The Impact of Out-of-home Leisure before Quarantine and Domestic Leisure during Quarantine on Subjective Well-being. Leis. Stud. 2021, 40, 321-337. [CrossRef]

22. Buonocore, C.; De Vecchi, R.; Scalco, V.; Lamberts, R. Influence of Recent and Long-term Exposure to Air-conditioned Environments on Thermal Perception in Naturally-ventilated Classrooms. Build. Environ. 2019, 156, 233-242. [CrossRef]

23. Emmanuel, R. Performance Standard for Tropical Outdoors: A Critique of Current Impasse and a Proposal for Way Forward. Urban Clim. 2018, 23, 250-259. [CrossRef]

24. Xiong, J.; Lian, Z.; Zhang, H. Physiological Response to Typical Temperature Step-changes in Winter of China. Energy Build. 2017, 138, 687-694. [CrossRef]

25. Ueno, T.; Ohnaka, T. Influence of Long-Term Exposure to an Air-conditioned Environment on the Diurnal Cortisol Rhythm. J. Physiol. Anthropol. 2006, 25, 357-362. [CrossRef] [PubMed]

26. Yu, J.; Ouyang, Q.; Zhu, Y.; Shen, H.; Cao, G.; Cui, W. A Comparison of the Thermal Adaptability of People Accustomed to Air-conditioned Environments and Naturally Ventilated Environments. Indoor Air 2012, 22, 110-118. [CrossRef]

27. Grigoriadou, E.T. The Urban Balcony as the New Public Space for Well-being in Times of Social Distancing. Cities Health 2021, 4, 1-4. [CrossRef]

28. Francisco, R.; Pedro, M.; Delvecchio, E.; Espada, J.P.; Morales, A.; Mazzeschi, C.; Orgilés, M. Psychological Symptoms and Behavioral Changes in Children and Adolescents during the Early Phase of COVID-19 Quarantine in Three European Countries. Front. Psychiatry 2020, 11, 1329. [CrossRef]

29. Asim, F.; Chani, P.S.; Shree, V. Impact of COVID-19 Containment Zone Built-environments on Students' Mental Health and Their Coping Mechanisms. Build. Environ. 2021, 203, 108107. [CrossRef]

30. Dzhambov, A.M.; Lercher, P.; Browning, M.H.; Stoyanov, D.; Petrova, N.; Novakov, S.; Dimitrova, D.D. Does Greenery Experienced Indoors and Outdoors Provide an Escape and Support Mental Health during the COVID-19 Quarantine? Environ. Res. 2021, 196, 110420. [CrossRef]

31. Centers for Disease Control and Prevention (CDCP). Cleaning and Disinfecting Your Facility. Available online: https://www.cdc. gov / coronavirus/2019-ncov/community/ventilation.html (accessed on 20 June 2021).

32. The Environmental Protection Agency. Available online: https://www.epa.gov/coronavirus/about-list-n-disinfectantscoronavirus-covid-19-0 (accessed on 12 October 2021).

33. Ineson, E.M.; Comic, D.; Kalmic, L. Towards a Hierarchy of Hotel Guests' In-room Needs. Int. J. Contemp. Hosp. Manag. 2019, 31, 4401-4418. [CrossRef] 